\title{
Eu odeio quem odeia... Considerações sobre o comportamento dos usuários brasileiros na 'tomada' do Orkut ${ }^{1}$
}

\author{
Suely Fragoso ${ }^{2}$ \\ Unisinos \\ suely@unisinos.br
}

\begin{abstract}
Resumo: Este trabalho recupera e organiza registros da 'tomada' do Orkut pelos brasileiros. $O$ artigo inicia com alguns dados sobre o uso da Internet no Brasil e provê uma breve descrição do Serviço de Rede Social (SRS) Orkut. A chamada Brazilian Invasion é apresentada a partir de registros obtidos no próprio Orkut, os quais testemunham por um alto nível de agressividade entre os usuários do Brasil e dos EUA. A violência das mensagens contraria o estereótipo pacífico e amigável dos brasileiros e serve como registro de um dos mais intensos conflitos culturais ocorridos no Orkut até o momento. Os trabalhos do sociólogo Roberto Da Matta funcionam como principal chave de leitura na tentativa de entender o protagonismo brasileiro em tais eventos.
\end{abstract}

Palavras-chave: Web; Redes sociais; Identidades Culturais

Abstract: This work attempts to provide some insight into the Brazilian Invasion of Orkut. To this end. the paper examines some data concerning Internet use in Brazil and then proceeds on to a brief description of the Social Networking Software (SNS) Orkut. To address the Brazilian Invasion, the paper uses, above all, the records of Orkut itself, which bear witness to a high level of hostility between users from Brazil and from the United States of America. The aggressiveness of the posts, contrary to the image of friendliness and pacifism of that Brazilians have, lead to some of the most violent battles in the clash of cultures set up in Orkut. Work by the Brazilian sociologist Roberto Da Matta provides the key to understand the Brazilian protagonism in those events.

Keywords: Web, Social networks, Cultural Identities.

\footnotetext{
${ }^{1}$ Este trabalho apresenta resultados parciais de uma pesquisa desenovlvida com o apoio do CNPq.

2 Professora do Programa de Pós-Graduação em Ciências da Comunicação da Unisinos. Pesquisadora CNPq. Ph.D em Comunicação pela University of Leeds, Inglaterra e Mestre em Comunicação e Semiótica pela PUC/SP.
} 
As primeiras conexões da Internet no Brasil foram estabelecidas tardiamente, em 1987³, sendo que apenas em 1995 o uso público e comercial da Internet foi regulamentado no Brasil. Outra década mais tarde, os brasileiros com acesso à internet ainda são proporcionalmente poucos 4 e estão fortemente concentrados nas áreas mais ricas e urbanizadas do país5. A intensidade da apropriação da Internet pelos usuários brasileiros, por sua vez, é excepcionalmente alta: em junho de 2005 os usuários brasileiros ultrapassaram o tempo de permanência online de qualquer outra nação estudada pela Nielsen/Netratings, chegando a superar as médias japonesa e estadunidensepor mais de uma e duas horas respectivamente ${ }^{6}$. Há indicativos de que boa parte desse tempo online é despendida com aplicativos de comunicação interpessoal, em suas três modalidades (um-a-um, um-a-todos ou todos-a-todos (Leite, 2005, s.p. e Ibope/Netratings, 2006a). A popularidade dos comunicadores instantâneos (MSN Messenger e ICQ), dos blogs e fotologs, dos sites das operadoras de telefonia móvel (utilizados para o envio de torpedos evitando cobrança) e das salas de bate-papo no Brasil é interpretada como um sinal de que os brasileiros se interessam mais pelo potencial da Internet como ferramenta de relacionamento do que como meio de distribuição de conteúdo (Magalhães, 2005, s.p.).

A longa permanência online e a concentração de usuários em poucos tipos de site (especialmente os sistemas de comunicação sincrônica, blogs, fotologs e, mais recentemente, os serviços de rede social, ou SRSs) favorecem a ocorrência do que é

3 Naquele ano, a FAPESP (Fundação de Amparo à Pesquisa do Estado de São Paulo) e o LNCC (Laboratório Nacional de Computação Científica) conectaram-se a instituições estadounidenses.

$4 \mathrm{O}$ número de usuários domésticos ativos no Brasil em dezembro de 2005 foi estimado pela Nielsen/Netratings em 12,2 milhões (Ibope/Netratings, 2005), o que corresponde a cerca de $6,6 \%$ dos aproximadamente 185 milhões de brasileiros que o IBGE acreditava existirem no final do mesmo ano. Esta figura duplica quando se considera o acesso a partir de terminais situados em locais de trabalho, de estudo ou em telecentros e outros pontos de acesso público (Saito e Valim, 2005).

5 De acordo com um estudo do GAID-FGV realizado em 2003, naquele ano $13.5 \%$ e $10.41 \%$ das casas das duas regiões mais ricas do Brasil, respectivamente Sul e Sudeste, estavam equipadas com computadores com acesso à Internet. Na região Norte, consideravelmente mais pobre, apenas $3.68 \%$ dos lares tinham computadores com acesso à rede (GAID-FGV, 2003, p. 43).

${ }^{6}$ O tempo médio por usuário doméstico em junho de 2005 no Brasil foi estimado em 16h54min, contra $15 \mathrm{~h} 35 \mathrm{~min}$ no Japão e $14 \mathrm{~h} 46 \mathrm{~min}$ nos EUA. Os outros países considerados na mesma pesquisa e que obtiveram médias inferiores às aqui reproduzidas foram Austrália, França, Alemanha, Itália, Espanha, Suécia, Suíça e Reino Unido. (Ibope/Netratings, 2006) 
conhecido internacionalmente como Brazilian Internet Phenomena, uma categoria específica de 'Internet memes'7 em que, sem nenhuma razão evidente para que isso aconteça, o número de usuários brasileiros de um serviço online ultrapassa largamente o número de usuários da nacionalidade original do serviço. O primeiro registro de uma tal ocorrência data de junho de 2003, quando o número de usuários brasileiros do Fotolog (http://www.fotolog.net) ultrapassou o contingente estadounidense. Àquela altura, uma desavença cultural sobre o modo 'correto' de utilizar o Fotolog já estava em curso: enquanto a maioria dos usuários estadunidenses do Fotolog eram retratados como "fotógrafos amadores intelectualizados, que publicam fotografia séria", dizia-se que a maioria dos floggers brasileiros eram garotas adolescentes "publicando imagens feitas com webcams retratando a si mesmas, seus amigos, seus animais de estimação e quetais” (Kahney, 2003, s.p.).

Softwares de rede social são particularmente suscetíveis a este tipo de acontecimento. De fato, um dos maiores e provavelmente o mais amplamente conhecido Brazilian Internet Phenomenon foi a invasão do serviço de rede social Orkut, que remonta aos primeiros dias daquele SRS, em 2004, e dois anos mais tarde não dá sinais de esmorecimento.

\section{A Invasão do Orkut}

O Orkut (http://www.orkut.com) é um serviço de rede social que foi lançado pelo Google em janeiro de 2004. Como a maioria dos outros aplicativos desse tipo, inclusive seu predecessor mais famoso, o Friendster, o Orkut foi concebido com base no modelo de pequenos mundos de Milgram (1967, descrito em Barabasi, 2002) e funciona coletando e registrando dados de associações entre seus usuários.

Para entrar no Orkut é preciso ser convidado por alguém que já seja um membro do serviço. Tendo aceito um convite, o usuário deve construir seu perfil pessoal. Perfis do Orkut são organizados em três camadas: perfil social (com informações como idade, gênero, nacionalidade, relacionamento, etc); perfil profissional (escolaridade, profissão, interesses profissionais, etc) e perfil pessoal (cor

\footnotetext{
7 'Internet phenomena' ou 'Internet memes' são ocorrências em que a popularidade de algo relativamente desconhecido cresce geométrica ou exponencialmente graças à propagação de conteúdo pela Internet. Internet memes geralmente iniciam e terminam de forma brusca e têm duração relativamente breve.
} 
do cabelo, cor dos olhos, tipo físico, o que chama a atenção em mim, etc). Uma imagem pode ser associada ao perfil. Todas as informações solicitadas são opcionais, ou seja, um usuário pode manter um perfil contendo e dando a ver o mínimo de informações, praticamente apenas o nome com o qual se registrou. Satisfeito, o usuário declara pronto seu perfil e acessa sua página pessoal no Orkut. No canto superior direito da página pessoal, uma janela mostra imagens dos amigos ao qual o usuário está vinculado (inicialmente, apenas aquele que lhe enviou o convite para o Orkut). Abaixo de cada imagem, os nomes funcionam como links que conduzem às páginas daquelas pessoas. Em todas as páginas pessoais do Orkut, as janelas mostram os amigos dos usuários com links que levam aos perfis dessas pessoas. Quando se encontra o perfil de alguém conhecido, a opção ‘+amigo' envia um convite interno que o outro usuário do Orkut encontrará - e aceitará ou não - na próxima vez que acessar o serviço.

Cada usuário tem também um álbum, capaz de abrigar até 12 imagens, e um livro de recados, onde outros podem deixar mensagens. Tanto o álbum quanto o livro de recados são visíveis para os demais usuários. Diferentemente de outros serviços de rede social, como por exemplo o Friendster, até muito recentemente o Orkut não disponibilizava informações sobre as visitas aos perfis. Esta possibilidade de xeretar o perfil, o álbum e os recados de outras pessoas certamente era um atrativo importante do Orkut, para cuja manutenção muitos perfis falsos foram criados após a implementação de 'visualizações de seu perfil' em abril de 2006. Outro diferencial do Orkut em relação a vários outros SRSs é a possibilidade de criar comunidades temáticas, que facilitam a identificação de usuários com interesses comuns, independentemente dos graus de separação entre eles.

Talvez o mais fascinante seja, no entanto, aquela que é a característica básica desse tipo de software de rede social, que é a 'corporificação' dos links entre as pessoas. Assim é que, após alguns minutos saltando de seus amigos para os amigos dos amigos, o usuário se vê diante de uma representação que explica até quase a obviedade a noção de 'seis graus de separação' formulada por Milgram (Barabasi, 2002). A rede de pessoas que então fica visível é freqüentemente exótica em sua diversidade e, quase invariavelmente, interessante de observar. 
Uma vantagem dos SRSs que funcionam apenas por convite é a pressuposta confiabilidade de todos os seus membros. Aliado à conceituação demasiadamente restritiva de identidade pessoal online que parece orientar o design do Orkut, esse fator explica o desestímulo à criação e manutenção de perfis pouco realistas. Os usuários do Orkut podem denunciar perfis que eles suspeitem ser falsos (a princípio entendidos como aqueles nos quais o usuário se identificou com nome ou imagem diferentes de sua identidade offline) ou cujos usuários tenham violado os Termos de Serviço (http://www.google.com/accounts/TOS). Apesar de terem sido considerado muito severos por alguns dos primeiros usuários (Hempell, 2004), os administradores do Orkut foram sempre muito mais condescendentes com os perfis fictícios que o Friendster $^{8}$.

Outro aspecto interessante do Orkut é a existência da área 'O que há de novo', que dá acesso a duas outras áreas distintas: anúncios (notícias sobre alterações no serviço, novidades relativas às normas de uso e quetais) e dados demográficos, um conjunto de gráficos de barras com estatísticas diárias sobre o perfil dos usuários do Orkut (Figura 2). A disponibilização dos dados demográficos provou ser um importante fator de atração para o Orkut: seguir as alterações no perfil geral dos usuários ao longo do tempo tornou-se um passatempo para muitos membros do serviço. Em março de 2004 foi criada uma comunidade dedicada exclusivamente ao registro e discussão das 'Estatísticas do Orkut' (Orkut Statistics ${ }^{9}$ ), a qual, em maio de 2006, contava 1.466 membros, responsáveis por mais de 150 tópicos que, juntos, somavam milhares de mensagens.

\footnotetext{
8 Johnatan Adams, criador do Friendster, era particularmente contrário aos assim chamados Fakesters. Em uma verdadeira cruzada contra os perfis falsos no Friendster, Adams deletou aqueles que usavam nomes de personagens históricos e ficcionais, que não tinham fotos realísticas, que descreviam a si mesmos com palavras ou imagens que ele considerava 'pouco apropriadas' ou mesmo os que estavam linkados a uma quantidade muito grande de outros usuários. Uma grave crise foi então instaurada, pois entre os Fakesters estavam alguns dos mais entusiásticos usuários do Friendster (Anderson, 2003, s.p.). $9 \mathrm{http} / / /$ www.orkut.com/Community.aspx? $\mathrm{cmm}=34264$
} 


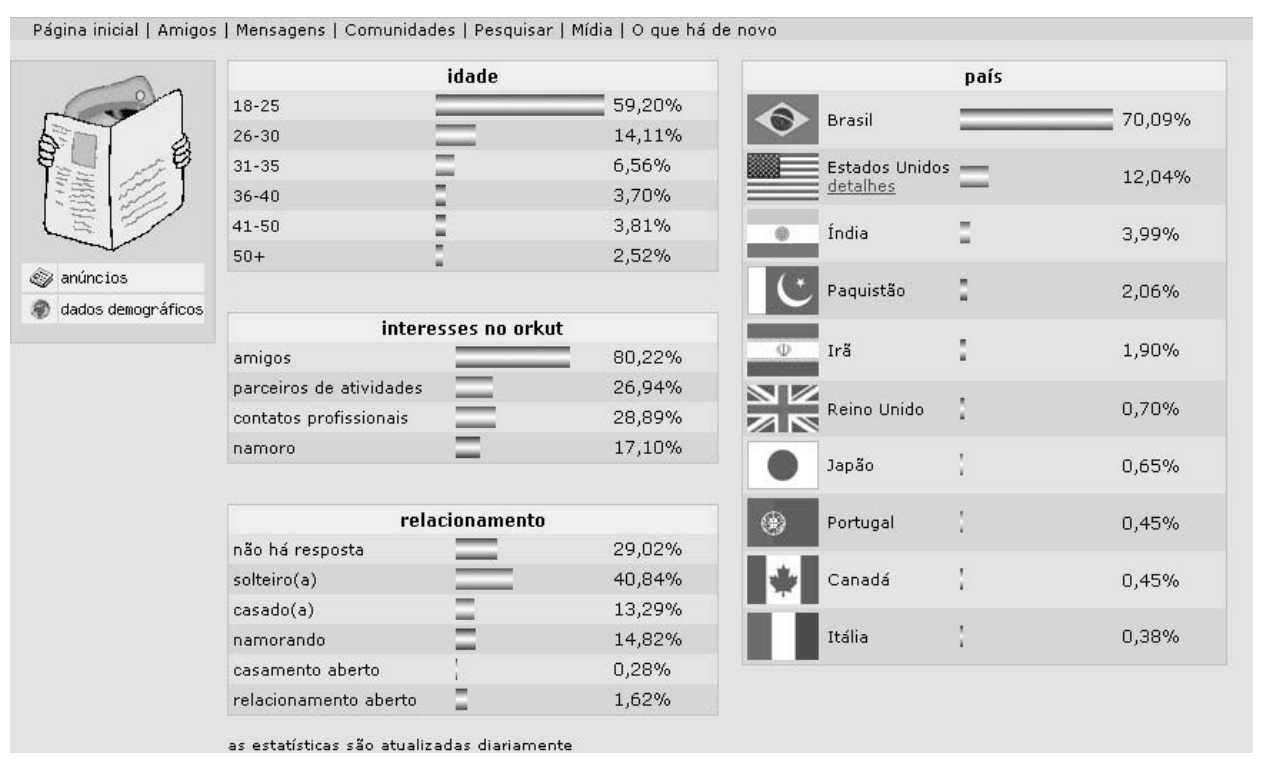

Figura 1: Área dados demográficos do Orkut em 17 de maio de 2006.

Em seus pouco mais de dois anos de existência, o Orkut agregou milhões de usuários num ritmo incrivelmente rápido (Figura 3). No início, a maioria dos usuários provinha dos EUA, mas conforme o número total de usuários do Orkut disparava, os perfis começaram a indicar uma internacionalização cada vez mais acentuada. Assim é que, em meados de fevereiro de 2004, mais que 60\% dos usuários do Orkut eram estadunidenses. Em seguida vinham os usuários do Reino Unido e Canadá, cada um com pouco mais de 3\%. Outros países em que o Orkut parecia inicialmente fadado ao sucesso eram a Holanda, Alemanha e Suécia. Na metade de abril de 2004, a parcela de usuários dos EUA estava reduzida a menos da metade do total de usuários, enquanto os membros do Japão e o Brasil tinham crescido para 7,4 \% e 7,2 \% respectivamente (Hempell, 2004, s.p.). Em maio do mesmo ano, os usuários dos EUA eram 43\% do total e a proporção de brasileiros $(15,02 \%)$ tinha quase triplicado a de japoneses, que caíra para 5,66\%. Próximo ao final de junho de 2004, a porcentagem de usuários brasileiros ultrapassou a de usuários estadunidenses. Daí para diante, as porcentagens de usuários brasileiros e estadunidenses do Orkut variaram em proporção inversa.

Conforme aumentava o número de brasileiros, crescia também o número de comunidades com títulos e tópicos em português: a primeira delas parece ter sido ' $\mathrm{Eu}$ 
ando com meus pés'10, criada logo após o lançamento do Orkut. Uma semana mais tarde, em 30 de janeiro de 2004, outro usuário criava aquela que parece ser a mais antiga comunidade a definir-se como brasileira e que é também uma das mais ativas do Orkut, contando 549.842 membros e mais de 10.000 tópicos em fevereiro de 2006. Intitulada simplesmente 'Brasil'11, em fevereiro de 2006 essa comunidade estava descrita como "um fórum para Brasileiros e qualquer um interessado no país e na cultura”.
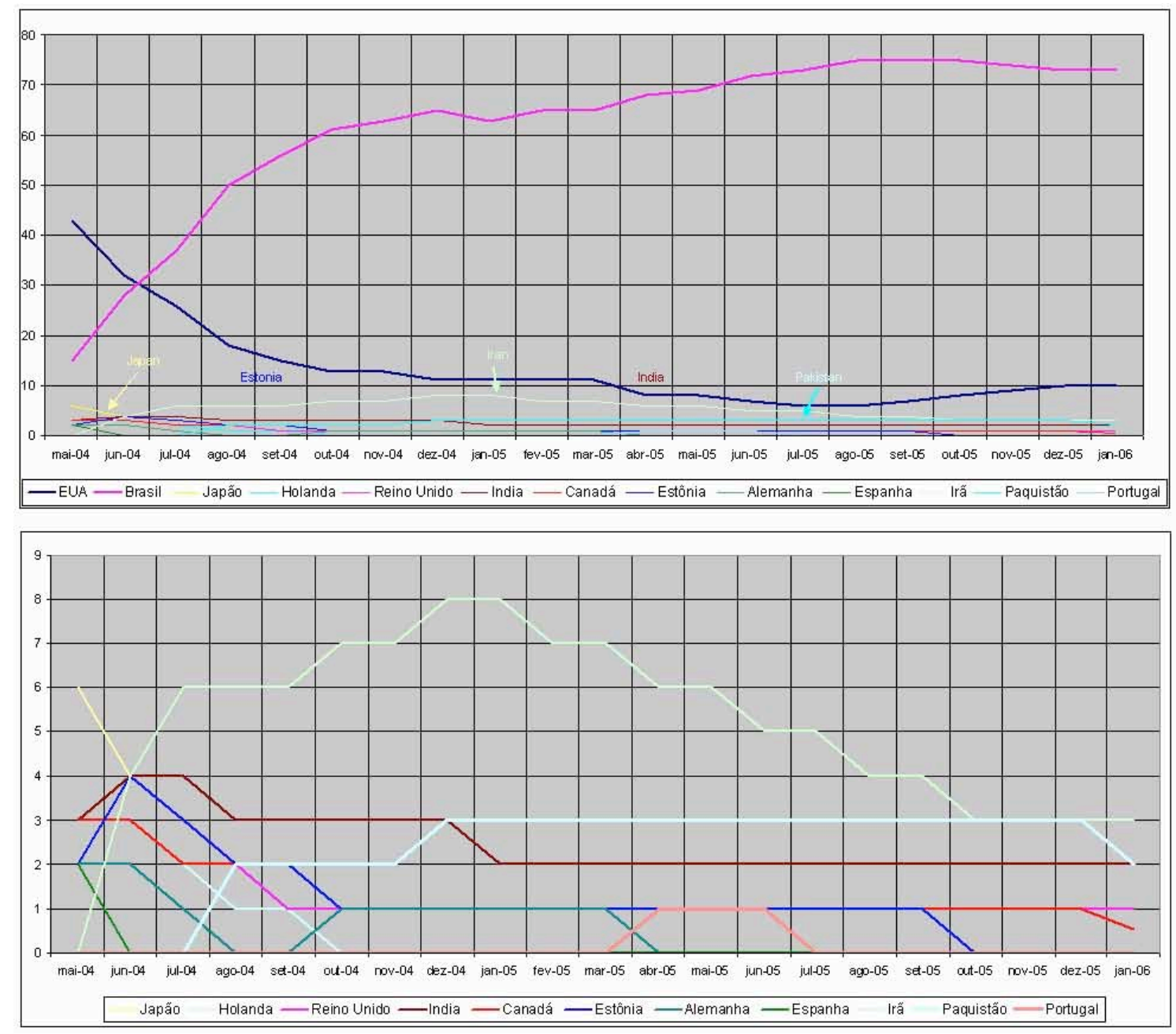

Figura 2: Porcentagens de usuários do Orkut por nacionalidade entre maio de 2004 e janeiro de 2006 ${ }^{12}$. No alto, dados das 13 nacionalidades que estiveram entre as 10 mais populosas durante aquele

${ }^{10} \mathrm{http}: / /$ www.orkut.com/Community.aspx? $\mathrm{cmm}=240$. Esta Comunidade foi criada em $23 \mathrm{de}$ janeiro de 2004 e contava 9.702 membros - mas apenas 30 tópicos - em fevereiro de 2006. ${ }_{11} \mathrm{http}$ // www.orkut.com/Community.aspx? $\mathrm{cmm}=4249$

12 No início de maio de 2004, membros da Comunidade Orkut Statistics começaram a registrar de forma consistente a porcentagem de usuários registrada nos códigos de barras da 
período: Estados Unidos, Brasil, Japão, Holanda, Reino Unido, India, Canadá, Estônia, Alemanha, Espanha, Irã, Paquistão e Portugal. Embaixo, excluídos os dados de usuários do Brasil e dos Estados Unidos.

As primeiras comunidades dedicadas a discutir o alto número de usuários brasileiros foram criadas ainda nos primeiros meses de funcionamento do Orkut. Não levou muito tempo para que o tom dos protestos se acentuasse, nem para o revide dos brasileiros, que passaram a criar comunidades anti-Estados Unidos (Tabela 1).

Aos moldes do que ocorrera nos primeiros meses do Orkut, quando os brasileiros se engajaram para tentar ultrapassar o número de usuários dos EUA, o segundo semestre de 2004 assistiu a um esforço em busca de um objetivo ainda mais ambicioso: atingir a maioria esmagadora de usuários brasileiros de modo a 'tomar' o Orkut dos estadunidenses. Criada em março de 2005 e contando com 3.959 membros em janeiro de 2006, a comunidade Brazilians Own Orkut13 conclama os usuários brasileiros a "Clicar em Convidar Amigos e convidar todos da sua lista de amigos a entrar aqui!" de modo a "reunir na comunidade o maior número possível de Brasileiros14". Com isto, a comunidade pretende ser "a way to show all the world how big Brazilians are and prove that we Own Orkut!" because "We are patriots and hate everyone who says we are a plague! Let us show our power!15" (Pedro Braz!, Fevereiro de 2006). Outras comunidades com propostas semelhantes foram criadas durante todo o ano de 2005, por exemplo O Brasil dominou o Orkut16 e O Brasil lidera o Orkut17.

área dados demográficos do Orkut. O Tópico Next change in nations top 10, da Comunidade Orkut Statistics (iniciado em 4/21/2004) foi a principal fonte de dados para este gráfico.

13 http://www.orkut.com/Community.aspx? $\mathrm{cmm}=1643152$.

${ }^{14}$ Em português no original.

15 Em inglês no original.

$16 \mathrm{http}$ ://www.orkut.com/Community.aspx? $\mathrm{cmm}=5632216$, criada em 8 de outubro de 2005 .

17 http://www.orkut.com/Community.aspx? $\mathrm{cmm}=6901646$, criada em 7 de dezembro de 2005. 
Tabela 1: Exemplos de comunidades relativas ao tema do alto número de brasileiros no Orkut criadas em 2004 e que ainda estão em atividade em 2006.

\begin{tabular}{|c|c|c|c|c|}
\hline $\begin{array}{l}\text { Nome da } \\
\text { Comunidade }\end{array}$ & Criação & Dono & Língua & $\begin{array}{l}\text { No de } \\
\text { Membros }\end{array}$ \\
\hline United States of Brazil & $04 / 25 / 04$ & Huy Zing & Inglês & 4,317 \\
\hline $\begin{array}{l}\text { WTF A Crazy Brazilian } \\
\text { Invasion }\end{array}$ & 05/07/04 & Gera Dikarev & Inglês & 2,696 \\
\hline $\begin{array}{l}\text { Too Many Brazilians in } \\
\text { Orkut }\end{array}$ & 05/16/04 & John. & Inglês & 1,211 \\
\hline $\begin{array}{l}\text { WTF a Crazy American } \\
\text { Implosion? }\end{array}$ & 06/15/04 & Huy Zing & Inglês & 120 \\
\hline USA Sucks & 06/20/04 & $\begin{array}{l}\text { Giuliano } \\
\text { Griffante }\end{array}$ & Português & 65 \\
\hline Brazilians, the Plague & 06/18/04 & $\begin{array}{l}\text { Marcio } \\
\text { Wilheim }\end{array}$ & Português & 507 \\
\hline $\begin{array}{l}\text { Eu Odeio os Estados } \\
\text { Unidos }\end{array}$ & 07/16/04 & Victor Brasil & Português & 8,174 \\
\hline $\begin{array}{l}\text { Why do you hate } \\
\text { Brazilians? }\end{array}$ & 07/18/04 & Jags R. & Inglês & 292 \\
\hline Brasil Sucks! & 07/17/04 & $\begin{array}{l}\text { Jonkatz /. } \\
\text { Troll }\end{array}$ & Inglês & 20 \\
\hline Brasil & o8/01/04 & July Fernandes & Inglês & 2,422 \\
\hline $\begin{array}{l}\text { Amazon is only Brazilian! } \\
\text { Ok? }\end{array}$ & 08/07/04 & Babi Barbara & Português & 3,114 \\
\hline $\begin{array}{l}\text { Eu odeio quem odeia o } \\
\text { Brasil }\end{array}$ & o8/30/04 & $\begin{array}{l}\text { Bruna Peres } \\
\text { Justino }\end{array}$ & Português & 6,407 \\
\hline $\begin{array}{l}\text { No Americans, Yes } \\
\text { Brazilians! }\end{array}$ & 09/11/04 & Diego Romão & Português & 80 \\
\hline Americans \& Brazilians & $11 / 18 / 04$ & Elias Chamoun & Inglês & 161 \\
\hline $\begin{array}{l}\text { Brasileiros: Vergonha do } \\
\text { Orkut }\end{array}$ & $12 / 23 / 04$ & Eric Saraiva & Português & 118 \\
\hline
\end{tabular}

Embora haja registro de venda de convites para o Orkut em sites de leilão (Badô, 2004, s.p.), a 'generosidade' com que os brasileiros convidavam outras pessoas para o Orkut aumentou conforme se acirrava a competição com os usuários estadunidenses e foi certamente um fator fundamental para a 'invasão verdeamarela'. Não era - e ainda não é - incomum encontrar pedidos e ofertas de convites para o Orkut em português espalhados por newsgroups, mailing lists, blogs, etc 
(Figura 3). Além disso, encontram-se perfis de usuários brasileiros com centenas de amigos - de fato, alguns têm milhares de amigos. Como cada perfil do Orkut não aceita mais que mil e algumas poucas conexões, não é raro que perfis brasileiros tenham nomes seguidos por I, II, II etc. Esta é uma estratégia para ultrapassar a restrição e acumular, em níveis máximos, o prestígio social implicado em caracterizar-se como um dos mais populares conectores do Orkut ${ }^{18}$.

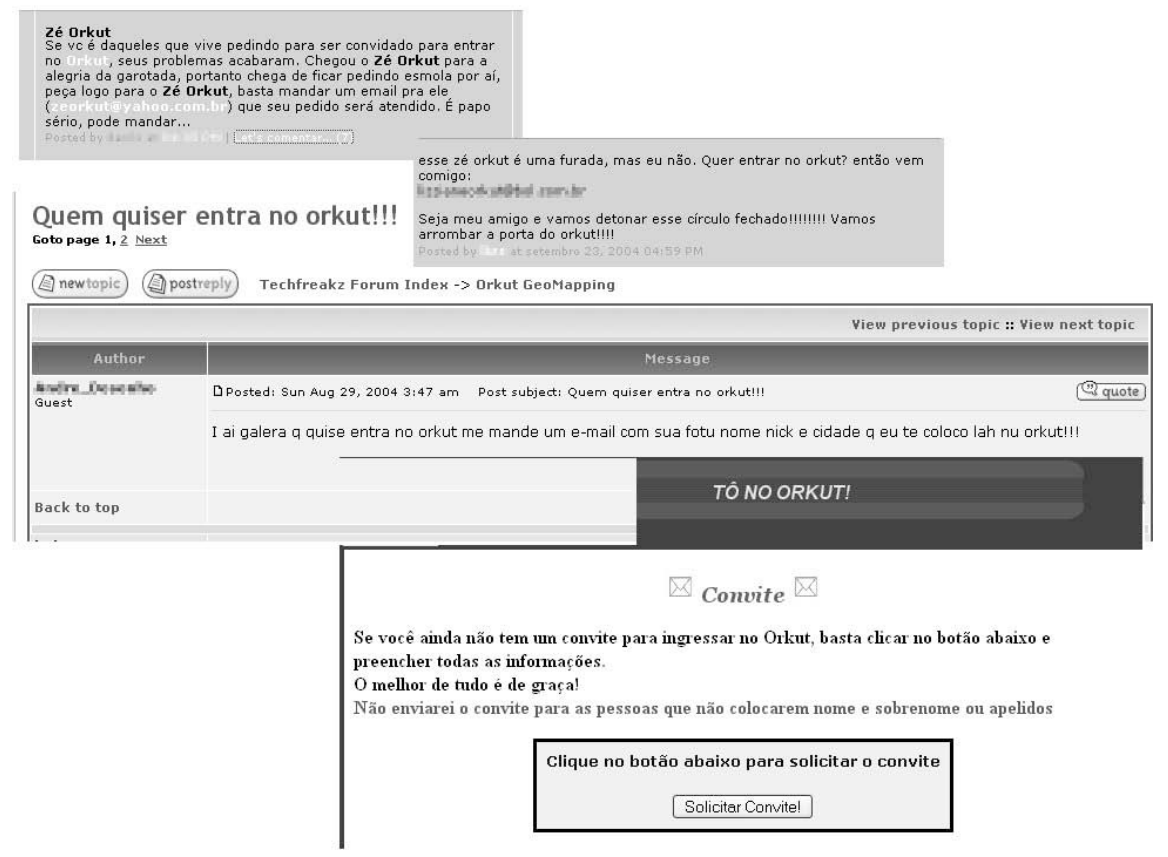

Figura 3: Exemplos de ofertas para entrar no Orkut disponíveis em sites brasileiros em 2006. No alto, mensagens em blogs, ao centro, tópico em fórum online e embaixo acesso a um formulário para envio automático de convites para o Orkut em um site intitulado "Tô no Orkut".

A facilidade com que os brasileiros enviam convites para o Orkut e o fato de que aceitam inclusive desconhecidos como seus 'amigos' foi um outro fator de irritação para usuários mais circunspectos, que consideravam o caráter de clube privativo uma parte importante do charme original do Orkut. A explicitação dos 'seis graus de distância' entre os usuários foi de fato arruinada pela enxurrada de brasileiros que se divertiram - e ainda se divertem - convidando qualquer um para entrar e conectando-se com todos os demais no serviço, colecionando 'amigos' aos milhares.

\footnotetext{
${ }^{18}$ Acumular tantas conexões quanto possível de fato não é o caminho mais eficaz para tornarse um dos principais conectores de uma rede, mas certamente é uma excelente maneira de parecer sê-lo.
} 


\section{E daí?}

O fato de um serviço online original de um dado país ter sido tomado por usuários de outra nacionalidade não é uma situação inusitada. Afinal, qualquer coisa publicada online está disponível para qualquer pessoa situada fisicamente num lugar onde haja uma conexão com a Internet. Certamente o apelo de qualquer serviço baseado na Web varia nas diferentes regiões do globo, conforme as especificidades culturais dos potenciais usuários. Porque favorecem o desejo de acumular conexões (como uma demonstração de prestígio social), os SRSs são particularmente suscetíveis a serem 'tomados' por usuários pertencentes a grupos pré-existentes. Assim é que, independentemente da invasão brasileira do Orkut, vários outros serviços similares que estavam previstos para crescer ao máximo dentro dos EUA antes de expandir-se internacionalmente também foram subitamente inundados com usuários de outras nacionalidades. É sabido que o Linkedin, por exemplo, cresceu mais e mais rapidamente na Islândia, Finlândia, Israel e Holanda, enquanto o Friendster foi inicialmente tomado por usuários das Filipinas (Glasner, 2005, s.p.).

O fato de o Orkut ter sido virado do avesso por uma profusão de perfis falsos e usos não autorizados, incluindo atividades ilegais, também não é nada novo: o mesmo aconteceu antes em diversos serviços de comunicação mediada por computador, por vezes dando origem a algumas das mais amplamente conhecidas lendas da cultura da internet. É difícil encontrar quem não tenha ouvido falar do estupro virtual em LambdaMOO (Dibbel, 1993, s.p.), do usuário que se apresentou como uma senhora paralítica e solitária num fórum e, sob este personagem, comoveu diversas usuárias (Stone, 1991, p. 82-83 apud Bechar-Israeli, 1995, s.p.) ou do email pedindo ajuda para evitar que a fortuna de um marido, cliente ou amigo recentemente morto seja confiscada por uma ditadura particularmente cruel num país africano.

O que há de realmente interessante na invasão do Orkut se deixa apenas entrever nas respostas tipicamente dadas a uma questão muitas vezes repetida: por que brasileiros? A imensa maioria das tentativas de resposta remete a imagens estereotípicas dos brasileiros. Um texto intitulado Top ten reasons orkut is popular in Brazil, publicado nas Orkut News em fevereiro de 2005, resume algumas das razões mais comumente mencionadas para a presença massiva dos brasileiros no 
Orkut: "we [Brazilians] know lots of people because we go out more often [than people from other countries]"; "we are really a fun and different people" e "we love to ... bring some warmth and "real stuff" to this virtual community" Finalmente, "we're a nice and friendly people and we're not afraid, like most other orkut users, to interact and exchange experiences with everybody else, no matter what country" (Silva, 2005, s.p.).

Até mesmo os acadêmicos tendem a recorrer aos estereótipos ao explicar porque o Orkut se tornou tão popular no Brasil: entrevistada pela Reuters, Elisabeth N. Saad Corrêa atribuiu o fenômeno ao fato de que "brazilians are naturally gregarious" (Alerigi, 2004, s.p.). Falando ao Universia Brasil, o sociólogo. Antonio Flávio Testa também atribui à "natureza do brasileiro", um povo "muito curioso e relacional”, a razão para sua desenvoltura com as ferramentas de relacionamento online (Testa em Marques, 2005, s.p.). Mesmo tendo elencado diversos fatores de ordens distintas para a popularidade do Orkut no Brasil, também Marcelo Coutinho não deixou de mencionar que os aplicativos para comunicação mediada por computador em geral tendem a ser populares entre os povos latinos, como os brasileiros, porque estes são mais comunicativos que os anglo-saxões (UOL, 2005, s.p.).

Em diversas Comunidades do Orkut, muitos usuários (a maioria deles brasileiros, mas por vezes também de outras nacionalidades) repetidamente associam a invasão do Orkut pelos brasileiros a características positivas de nosso povo, que se diz ser amigável e alegre. Observando o comportamento dos usuários brasileiros no Orkut, entretanto, essas descrições parecem, na melhor das hipóteses, sarcásticas. Muitas comunidades, tópicos e mensagens criadas por uma parcela significativa de usuários brasileiros no Orkut testemunham por um alto grau de instransigência, sobretudo (mas não apenas) para com os estrangeiros, notadamente os estadunidenses (Figura 4). 


\section{(e) compós}

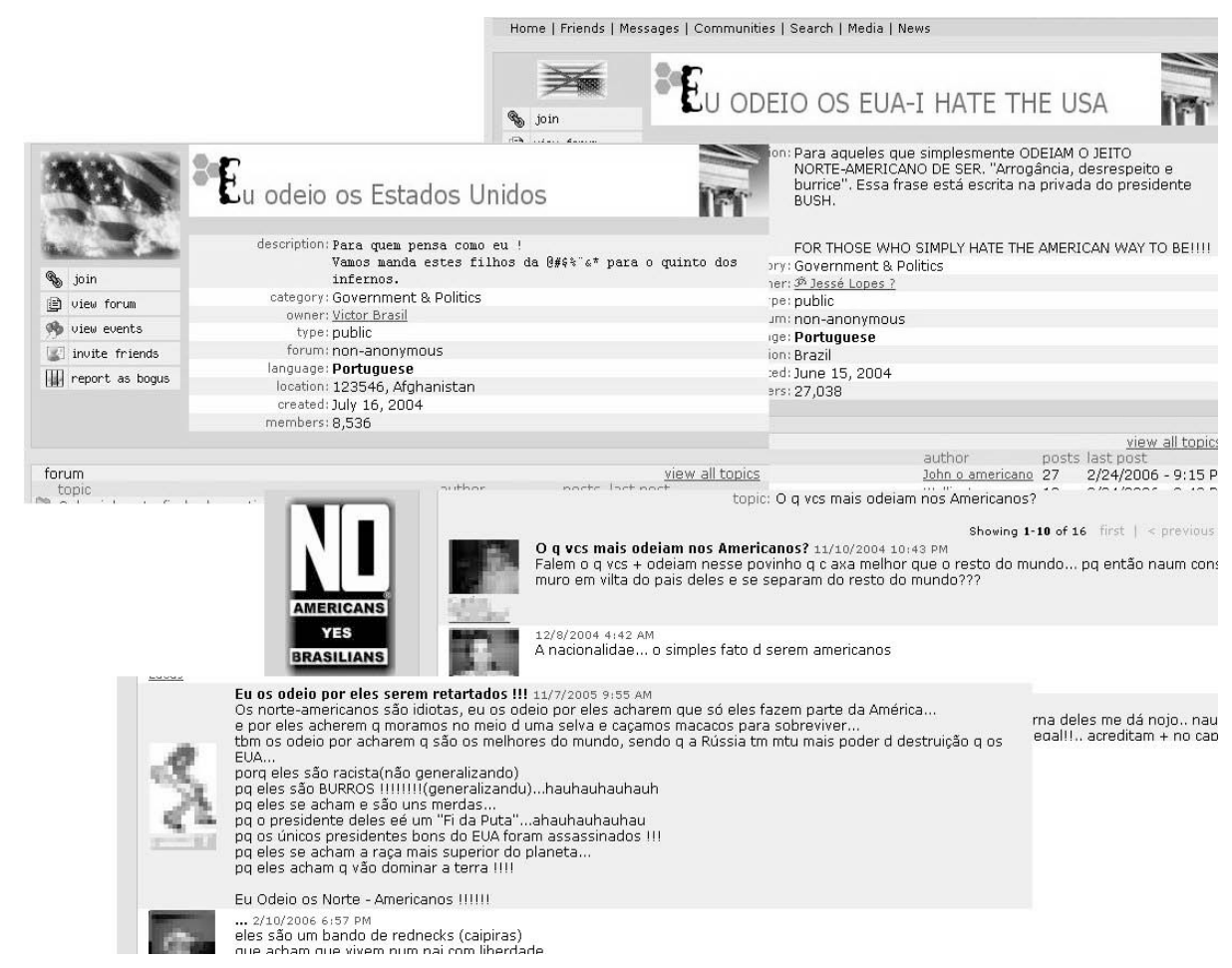

Figura 4: Exemplos de comunidades e mensagens anti-EUA. Em cima, destaque para a descrição de duas comunidades: à direita, 'Eu Odeio os EUA - I Hate the USA ${ }^{19}$, mais abaixo, 'Eu Odeio os Estados Unidos $^{20}$. Embaixo, exemplos de mensagens datadas de 2004, 2005 e 2006 na Comunidade "NO Americans Yes Brazilians ${ }^{21}$, Tópico “O que vcs mais odeiam nos Americanos?”.

Para discutir este fenômeno com propriedade, é preciso antes de mais nada reconhecer que a nacionalidade está longe de ser uma fonte primária de identificação. Afinal, os Estados-Nação modernos resultaram de processos relativamente recentes e muitas vezes violentos de subordinação das diferenças com vistas à construção de uma comunidade nacional aparentemente coesa. É verdade que a associação entre natividade e soberania transformou os Estados-Nação em fontes fundamentais - mas não por isso menos artificiais ou tensas - de significados para as identidades culturais modernas (Bauman, 2005, p. 25). No caso dos confrontos entre brasileiros e estadunidenses no Orkut, as identidades nacionais em jogo parecem pontos de apoio particularmente frágeis. Afinal, tanto o Brasil quanto os EUA resultam da unificação relativamente recente de territórios do Novo Mundo, cujos habitantes nativos foram

19 http://www.orkut.com/Community.aspx?cmm=95875, criada em 15 de junho de 2004. ${ }_{20} \mathrm{http://www.orkut.com/Community.aspx?cmm=174663,} \mathrm{criada} \mathrm{em} 16$ de julho de 2004. ${ }^{21} \mathrm{http}$ ://www.orkut.com/Community.aspx? $\mathrm{cmm}=409912$, criada em 09 de novembro de 2004. 
subjugados até perderem completamente a significação quantitativa diante das populações colonizadoras. Os povos brasileiro e estadunidense compõem-se, hoje, quase que exclusivamente pelos descendentes dos colonizadores europeus, dos escravos africanos e de outros imigrantes mais recentes, esses com etnias as mais diversas. Que as vozes desses cadinhos multi-étnicos - e, em grande medida, multiculturais - se elevem tomando as respectivas identidades nacionais como sua maior motivação e seu grito de guerra é, no mínimo, paradoxal. Mais surpreendente ainda é verificar que é de parte dos brasileiros que emergem algumas das manifestações mais violentamente xenófobas nas comunidades do Orkut. Afinal, trata-se de um povo que se orgulha tanto de sua índole pacífica e amigável quanto da multiplicidade de hibridismos que perpassam sua cultura e constituem a experiência do Brasil (desde a culinária até a religião, atravessando inclusive a língua-pátria e a mestiçagem racial).

Em muitos casos, as identidades nacionais aparecem nos tópicos e mensagens das Comunidades do Orkut como os gritos de guerra de uma luta defensiva, em que um grupo menor e mais fraco (no caso, os brasileiros) estaria se opondo ao jugo de um grupo maior e mais poderoso (os estadunidenses). Esta construção dispõe de uma tal consistência histórica que se torna quase inevitável aceitá-la como resposta: assim entendida, a agressividade dos brasileiros contra os estadunidenses no Orkut expressaria os rancores cultivados pelo 'imperalismo americano' durante muitas décadas. De fato, algumas manifestações anti-EUA expressam de forma bastante direta ressentimentos relativos à política internacional nos governos G. W. Bush, com inevitáveis menções à invasão do Iraque e ao descumprimento do Protocolo de Kyoto. Também não é difícil encontrar mensagens que remetem a antipatia aos EUA às injunções estadunidenses na América Latina durante a Guerra Fria:

\author{
'Não a Quioto? Toma o Katrina'22 \\ ‘Torturas no Iraque, que vergonha !!’23 \\ 'Imperialistas filhos da puta!!!’24
}

\footnotetext{
22 Nome de Comunidade criada em 18 de setembro de 2005, http://www.orkut.com/Community.aspx? $\mathrm{cmm}=5121731$.

23 Tópico criado em 28 de julho de 2005, na Comunidade 'Eu Odeio os Estados Unidos', 2 de setembro de 2004 http://www.orkut.com/Community.aspx? cmm=370032.
} 
Uma observação mais sistematizada das manifestações agressivas dos brasileiros no Orkut permite perceber, no entanto, que na imensa maioria das vezes o alvo da violência não é exatamente os EUA, mas a língua inglesa. É praticamente impossível desconhecer - ou mesmo discordar - que o inglês é a língua mais utilizada para a comunicação intercultural nos dias de hoje. Vale a pena lembrar, porém que, embora o total de pessoas capazes de se comunicar em inglês ${ }^{25}$ fosse estimado em cerca de um bilhão de pessoas no final do século XX (Ianni, 1999, p. 59), este número representa apenas cerca de $15 \%$ da população mundial, estimada em 6 e meio bilhões de pessoas em fevereiro de 2006 (United States Department of Commerce, 2006). É evidente que mesmo entre esses $15 \%$ há variações no sentido de compreender o inglês falado e ler, falar e escrever em inglês mais ou menos bem. Os brasileiros, em sua maioria, conhecem muito pouco a língua inglesa. Diferentemente do que muitos estrangeiros imaginam, o inglês não é amplamente utilizado no Brasil (nem, possivelmente, na maior parte dos países da América do Sul).

Uma vez que noções básicas de língua inglesa são normalmente ensinadas na escola brasileira, dado que os usuários da Internet no Brasil pertencem às famílias de maior renda e detêm os mais altos níveis de escolaridade, não surpreende que a maioria dos usuários brasileiros do Orkut seja capaz de ler as interfaces e algumas mensagens escritas em inglês. Daí a ser capaz de expressar-se por escrito em inglês nas Comunidades, com a fluência necessária para sustentar argumentações com os falantes nativos, há com certeza uma distância bastante grande. Ocorre que a comunicação mediada por computador viabilizou a experiência em primeira pessoa do encolhimento do mundo e aproximação das culturas para uma significativa parcela da elite brasileira cujos horizontes não contemplam deslocamentos internacionais de grande escala - e, como se sabe, o contato cultural tem na instabilidade sua característica mais estimulante e mais desestabilizadora. Afinal, a interação ou a presença em meio a estranhos implica situar-se nos limites da inadequação:

\footnotetext{
24 Tópico criado em 19 de maio de 2004, na Comunidade 'Anti-bush \& USers', 9 de abril de 2004, http://www.orkut.com/Community.aspx? cmm=39450.

25 Esta noção abrange indiscriminadamente os falantes nativos, aqueles para quem o inglês é a segunda língua e também os que o têm como língua estrangeira.
} 
estar total ou parcialmente "deslocado" em toda parte, não estar totalmente em lugar algum (ou seja, sem restrições e embargos, sem que alguns aspectos da pessoa "se sobressaiam" e sejam vistos por outras como estranhos) pode ser uma experiência desconfortável. . . . Sempre há alguma coisa a explicar, desculpar, esconder, ou, pelo contrário, corajosamente ostentar, negociar, oferecer e barganhar. Há diferenças a serem atenuadas ou desculpadas ou, pelo contrário, ressaltadas e tornadas mais claras. As "identidades" flutuam no ar, algumas de nossa própria escolha, mas outras infladas e lançadas pelas pessoas em nossa volta, e é preciso estar em alerta constante para defender as primeiras em relação às últimas. (Bauman, 2005, p. 19).

Numa tal situação, não basta a capacidade de entender o que os outros têm a dizer - expressar as próprias idéias é essencial para sentir-se reconhecido, de forma tangível, pelos demais. Reduzidos à invisibilidade pela impossibilidade de expressarse, provavelmente muitos usuários brasileiros já abandonaram diversos serviços de rede social. No Orkut, entretanto, as indicações dos dados demográficos e as menções pela grande mídia apontaram desde cedo para uma grande possibilidade de que alguns ou vários outros usuários de uma comunidade qualquer fossem também brasileiros. A própria estruturação do Orkut permite verificar suposições desse tipo seguindo os links para os perfis de outros usuários de uma comunidade. Ora, constatada a presença de outros brasileiros, escrever em língua portuguesa permitiu a esses usuários reconquistar, ainda que parcialmente, a visibilidade perdida.

Seria de se supor que, diante de um tal quadro, começassem a multiplicar-se as comunidades em língua portuguesa, replicando os temas até então discutidos em inglês. Esta ocorrência poderia ter conduzido a uma guetificação do Orkut, em que os diferentes grupos de usuários tenderiam a separar-se por nacionalidade - ou, mais precisamente, conforme suas línguas nativas. Embora um grande número de comunidades em Português tenham realmente sido criadas, estranhamente a existência das mesmas não levou os brasileiros a abandonar as comunidades em língua inglesa, a deixar de escrever nelas em português ou a abrir mão de argumentar, muitas vezes de forma extremamente agressiva, pelo seu suposto ‘direito’ de fazê-lo:

Tammy Soldaat, a Canadian, got a sample of Brazilian wrath recently when she posted a message asking whether her community site on body piercing should be exclusive to people who speak English. 
Brazilian Orkut users quickly labeled her a "nazi" and "xenophobe."

"After that I understood why everyone is complaining about these people, why they're being called the 'plague of Orkut,"' she said in a site called "Crazy Brazilian Invasion".(Alerigi, 2004, s.p.)

Em 2006, continuam disponíveis no Orkut diversos registros de ocasiões em que um 'dono' de Comunidade apela aos Brasileiros para que se atenham à comunicação na língua oficial daquele grupo. Na maior parte das vezes, tais apelos são ignorados pelos usuários Brasileiros, numa atitude aparentemente análoga àquela expressa por Silva (2005, s.p.) ao abordar a questão dos perfis falsos em em seu texto Top ten reasons orkut is popular in Brazil: "we know this is wrong, but why play by the rules if this is a place for fun and entertainment?" De fato, são muitos os casos em que os brasileiros agem como se as regras do Orkut não lhes dissessem respeito. Uma interessante interpretação desse comportamento pode ser encontrada em um conjunto de obras do antropólogo brasileiro Roberto Da Matta (1978,1984,1985), que identifica na permanente necessidade de equilibrar-se entre instituições e valores em princípio incompatíveis as raízes da capacidade brasileira para viver não apenas entre duas lógicas opostas, mas para aderir a ambas e a cada uma delas ao mesmo tempo.

Para Da Matta, as origens desta disjunção essencial e conformadora da realidade brasileira remontam à instituição, no Brasil, de um aparato de Estado através do qual se pretendia construir um determinado tipo de sociedade, em oposição a um Estado que respondesse aos anseios da estrutura social que lhe dá origem e sustentação. A própria prática de equacionar todos como iguais perante a lei, condizente com a tradição igualitária das culturas anglo-saxônicas, ia de encontro a uma moralidade que nunca deixou de estar vigente no Brasil e segundo a qual uma “pessoa é importante porque pertence a uma família e tem compadres e amigos. É a relação que ajuda a definí-la como ser humano e como entidade social significativa. $\mathrm{Na}$ moralidade individualista moderna, porém, inaugurada com a Reforma [Protestante] e com a Revolução Industrial, a família e a sociedade é que eram constituídas de indivíduos ${ }^{26}$." (Da Matta, 1984, p.45, ênfase adicionada) O resultado é

\footnotetext{
${ }_{26}$ Para acompanhar o raciocínio de Da Matta, é necessário ter clareza sobre a distinção entre as noções de indivíduo e de pessoa que aquele autor toma como ponto de partida. Por
} 
o sistema institucional divorciado da prática cotidiana com o qual convivemos diariamente.

No Brasil, diferentemente tanto das sociedades baseadas em clãs ou castas que excluem sistematicamente a noção de indivíduo - quanto das sociedades ocidentais individualistas - que excluem 'a pessoa' -, as duas categorias convivem, perpetrando um código duplo (Da Matta, 1978, p. 190). As duas lógicas e as morais a elas associadas dão origem a uma experiência social organizada conforme um paradoxo de " leis que devem valer para todos e relações que evidentemente só podem funcionar para quem as tem. O resultado é um sistema social dividido e até mesmo equilibrado entre duas unidades sociais básicas: o indivíduo (o sujeito das leis universais que modernizam a sociedade) e a pessoa (o sujeito das relações sociais, que conduz ao polo tradicional do sistema)" (Da Matta, 1984, p.95-96).

Apelar, num tal sistema, para as regras universais - como fazem os donos das Comunidades do Orkut ao lembrar os usuários brasileiros da existência de uma língua padrão para a comunicação em áreas daquele SRS - é recusar-se a conceder a distinção de 'familiaridade' com que cada usuário está acostumado: trata-se, afinal, dos brasileiros de maior renda e escolaridade, por pressuposto, na esfera nacional, os mais bem relacionados. Assim é que fazer valer para todos a mesma determinação impessoal, recusando-se a abrir exceções em nome de razões relacionais (muitos outros usuários também são brasileiros) ou emotivas (por que eu não posso falar português se eu quero?), pode ser justo para o ethos anglosaxão, mas aparece como uma violência para diversos usuários brasileiros. Afinal, a aplicação da regra geral, impessoal, tende a funcionar entre os brasileiros como um eufemismo para a negativa ou como um modo de informar ao outro de sua condição de anonimato e

'indivíduo', Da Matta compreende a entidade autônoma e independente, "capaz portanto de pretender a liberdade e a igualdade, sendo a solidão e o amor dois de seus traços básicos" "e o poder de optar e escolher, um dos seus direitos mais fundamentais" Nesta construção, "a sociedade deve estar a serviço do indivíduo, o contrário sendo uma injustiça que importa corrigir" (Da Matta, 1978, p, 181-182).

A noção de pessoa, por sua vez, enfatiza o pertencimento social do sujeito. Aqui, não se trata da igualdade paralela de todos, mas "da complementaridade de cada um para formar uma totalidade que só pode ser constituída quando se tem todas as partes. Em vez de termos a sociedade contida no indivíduo, temos o oposto, o indivíduo contido e imerso na sociedade" "A noção de pessoa pode então ser sumariamente caracterizada como uma vertente coletiva da individualidade, uma máscara que é colocada em cima do indivíduo ou entidade individualizada (linhagem, clã, família, metade, clube, associação, etc) que desse modo se transforma em ser social.” (Da Matta, 1978, p, 182). 
inferioridade. Isto porque, no Brasil, "o que sempre se espera em qualquer situação de conflito ou disputa é o ritual do reconhecimento que humaniza e personaliza as situações formais, ajudando a todos a hierarquizar as pessoas implicadas na situação" (Da Matta, 1985, p. 87, ênfase adicionada).

Os brasileiros que ignoram a língua oficial de uma Comunidade ou mesmo os pedidos de atenção a ela por parte de seu dono, não consideram necessariamente que a regra esteja errada ou inadequada. Compreendem, no entanto, que, assim como ocorre com frequência no mundo 'do lado de lá da tela' de seus computadores, a lei pode ser esquecida, ou pelo menos anestesiada, de modo que não se aplique ao seu caso. Para Da Matta, não se trataria exatamente de cinismo inconsequente por parte dos usuários brasileiros, mas de um modo aprendido e praticado cotidianamente para viver, e às vezes sobreviver, numa nação em que "as leis formais da vida pública nada têm a ver com as boas regras da moralidade costumeira que governam a nossa honra, o respeito e, sobretudo, a lealdade que devemos aos amigos, aos parentes e aos compadres." (Da Matta, 1984, p. 104). Ignorar a determinação de escrever em inglês nas comunidades definidas para esta língua seria, assim, um modo tipicamente brasileiro de conciliar uma ordem impossível de ser cumprida expressar-se em inglês - com o desejo de permanecer no Orkut e interagir em qualquer uma de suas comunidades.

Sendo assim, no entanto, como explicar que foram também usuários brasileiros que inundaram as comunidades do Orkut com respostas violentas e incontáveis mensagens recheadas de palavrões, tornando o ambiente do SRS notadamente mais hostil?

Da Matta associa o comportamento negativo dos brasileiros em relação à rua e às coisas impessoais que nela se encontram ao fato de que, ao contrário do ambiente seguro e familiar da casa, "a rua é local de indesejável individualização, de luta e de malandragem. Zona onde cada um deve zelar por si . . . [pois] não se pode mais utilizar como moldura moral a vertente relacional e hierarquizante de nosssa constelação de valores. Mas falar que 'cada um está por si' equivale a abrir mão de um controle social rígido que de certo modo garante a pacificação dos ânimos e provê a ordem das coisas". (Da Matta, 1985, p. 61) Numa cultura em que o individualismo e a igualdade de direitos e deveres são vistos como valores negativos, qualquer local 
público - como é o caso do Orkut - é 'terra de ninguém', onde comportamentos que seriam impensáveis no território doméstico podem passar a ser, senão adequados, pelo menos aceitáveis.

Existiria assim, entre os brasileiros, uma pré-disposição para a agressividade no ambiente público do Orkut, que se vê acentuada pela emergência de um nacionalismo étnico que, como visto, responde a uma sensação de alienação ou exclusão e injustiça que é típica das zonas de intercâmbio cultural. As 'identidades de resistência' tipicamente recorrem à construção de "trenches of resistence and survival on the basis of principles different from, or opposed to, those permeating the institutions of society" (Castells, 1998, p.8), que é tipicamente o que fazem os brasileiros no Orkut.

Enquanto as agressões partem de um povo cujo estereótipo fala de transgressões da ordem de tipo carnavalesco (que, por definição, não têm consequência para a vida 'real') e, coerentemente, não ultrapassam as fronteiras do ambiente virtual do Orkut, chega a ser possível encarar com uma certa boa vontade as tentativas brasileiras de inverter os termos do que consideram ser a lógica opressiva de um dominant social group do Orkut.

Dominado, em 2006 o Orkut realmente ‘é brasileiro'. Muitas comunidades que discutiam a Brazilian Invasion estão reduzidas a escombros por onde circulam, vitoriosos, os usuários que as 'tomaram'. Os 'heróis da resistência norte-americana', que mantêm acesa a discórdia nesses ambientes são, em sua maior parte, fakesters, ao que tudo indica brasileiros saudosos da adrenalina dos tempos de batalha. Emergem, porém, novas chamadas para 'tomada do Orkut', que nos ajudam a lembrar que a "exclusão dos exclusores pelos excluídos" (Castells, 1998, p.9) não altera significativamente a ordem das coisas, apenas reforça as separações e enfatiza as fronteiras, potencialmente acirrando ainda mais os ânimos. Aproximando-se, em número de usuários, dos norte-americanos, os orkuteiros do Oriente Médio (proporcionalmente representados pelos iranianos, indianos e paquistaneses) ensaiam uma reedição, a seu modo, da Brazilian Invasion. Menos carnavalescamente, o principal tema em pauta deixou de ser a língua utilizada para comunicação no Orkut, para dar lugar a inúmeras comunidades, tópicos e mensagens discutindo questões mais agudamente vinculadas ao cotidiano internacional fora das 
redes. Será o ambiente do Orkut capaz de promover a comunicação intercultural ou está ele fadado a servir novamente como campo de batalha para identidades em confronto, acirrando ainda mais as diferenças e intensificando os estranhamentos?

\section{Referências Bibliográficas}

ALERIGI, A. 2004, Brazil Internet Craze Angers English Speakers. Reuters' report 17 July, 2004. Cópia disponível online em http://www.ladlass.com/ice/archives/oo8610.html [Jan 06]

ANDERSON, L. 2003, 'Attack of the Smartasses', SFWeekly, Aug 13, 2003. Disponível online em http://www.sfweekly.com/ [Dez 05]

ANTUNES, A. 2004, 'Brazilians in orkut', Orkut News, Quarta-feira, o8 de Dezembro de 2004. Disponível online em http://media.orkut.com/columns/ooo8.html [Jan 06]

BADÔ, F. 2004, Folha de S. Paulo, 30 de junho de 2004. Disponível no arquivo online da Folha de S. Paulo em http://www.folha.uol.com.br [acesso restrito] [Jan 06]

BARABASI, A.-L. 2002, Linked. New York, Plume.

BAUMAN, Z. 2005, Identidade. Entrevista a Benedeto Vecchi. Rio de Janeiro, Jorge Zahar.

BECHAR -ISRAELI, H. 1995, 'FROM < Bonehead > TO < cLoNehEAd > :NICKNAMES, PLAY, AND IDENTITY ON INTERNET RELAY CHAT', Journal of Computer Mediated Communication - JCMC, 1(2), Play \& Performance in ComputerMediated Communication, Setembro de 1995. Disponível online em http://jcmc.indiana.edu/vol1/issue2/index.html [Fev 06]

CASTELLS, M. 1998, The Power of Identity: The Information Age: Economy, Society and Culture, Vol. II. Oxford, Blackwell.

DA MATTA, R. 1978, Carnavais, Malandros e Heróis: para uma sociologia do dilema brasileiro. Rio de Janeiro, Guanabara Koogan.

DA MATTA, R. 1984, O que faz o Brasil, Brasil? Rio de Janeiro, Rocco.

DA MATTA, R. 1985, A Casa e a Rua. Rio de Janeiro, Guanabara Koogan.

Dibell, J. 1993, 'A Rape in Cyberspace', Village Voice, Vol. XXXVIII, No. 51, 21 de Dezembro de 1993. Disponível online em http://www.ludd.luth.se/mud/aber/articles/village voice.html [Fev 06]

GAID-FGV, 2003, Mapa da exclusão digital. Coordenação M. C. Neri. Rio de Janeiro,FGV/IBRE, CPS. Relatório disponível online em http://www.fgv.br [Mai 03] e dados complementares em CD-ROM.

GARCIA-CANCLINI, N. 2003, Culturas Híbridas: estratégias para entrar e sair da modernidade. São Paulo, Edusp.

GLASNER, J. 2005, 'We're a Hit in Manila! Now What?' Wired News 31 de Março de 2005. Disponível online em http://www.wired.com/ [Dez 05] 
HEMPELL, A. 2004, Orkut at eleven weeks: An exploration of a new on-line social network community. Disponível online em http://www.anthonyhempell.com/papers/orkut/ [Fev 04]

HUNTINGTON, S.P. 1996, The Clash of Civilizations and the Remaking of World Order. New York, Touchstone.

IANNI, O. 1999, 'Sociedade Global, história e transculturação' in J.V.T. dos Santos (org.), Violência em tempo de globalização. São Paulo, Hucitec, p. 43-64.

IBGE 2006, Instituto Brasileiro de Geografia e Estatística. Disponível online em http://www.ibge.gov.br [Mai o6]

IBOPE/NETRATINGS, 2006a, 'Novo recorde de navegação no acesso residencial da Internet no Brasil', IBOPE/NetRatings, Internet, Notícias, 04/01/2006. Disponível online em http://www.ibope.com.br [Mai 06]

IBOPE/NETRATINGS, 2006b, 'Internet residencial brasileira cresceu 12,4\% durante o ano de 2005', IBOPE/NetRatings, Internet, Notícias, 18/01/2006.

Disponível online em http://www.ibope.com.br [Mai 06]

KAHNEY, L. 2003, 'Fotolog: where Art meet T\&A', Wired News, o9 de Junho de 2003. Disponível online em http://www.wired.com [Fev 06]

LEITE, P. 2005, Site de relacionamento supera e-mail no país. Folha de S. Paulo, 15/07/2005. Disponível online em http://www.folha.uol.com.br [Fev 06]

MAGALHÃES, A. 2005, 'O que esperar da Internet nos próximos anos?' Wnews. Disponível online em http://www.wnews.com.br/site/colunas [Fev o6]

MARINI, A.R. 2006, 'TV Por assinatura: perto de casa, longe do bolso' in Fórum Nacional pela Democratização da Comunicação, Boletim E-Fórum, 85, 27 de Janeiro de 2006. Disponível online em http://observatorio.ultimosegundo.ig.com.br/artigos.asp?cod=366TVQo02 [Fev 06]

SAITO, A.C. and C.E. VALIM 2005, 'Internauta brasileiro tem recorde de acesso', Gazeta Mercantil 25 de Novembro de 2005, 'Caderno C', p. 1. Disponível online em http://www.cgi.br/infoteca/clipping/2005/midia124.htm [Jan 06]

SILVA, J. G. B. da, 2005, 'Top Ten Reasons orkut is Popular in Brazil', Orkut News, 23 de Fevereiro de 2005. Disponível online em http://media.orkut.com/articles/0109.html [Dez 05]

TORRES, R. 2005, 'Brazilians in orkut, No. 2', Orkut News, o9 de Fevereiro de 2005. Disponível online em http://media.orkut.com/articles/0100.html [Fev 05]

UNITED STATES DEPARTMENT OF COMMERCE, 2006, US Census Bureau. Disponível online em http://www.census.gov [Fev 06]

UOL 2005, Bate-Papo com Marcelo Countinho, 18 de April de 2005. Uma cópia do chat foi publicada pelo Ibope/Netratings: Confira a íntegra do chat com Marcelo Coutinho. Disponível em http://www.ibope.com.br/ [Jan 06]

ZILVETI, M. 2004 "Fotoblogue vira mania entre brasileiros", Folha de S. Paulo, 14 de Julho de 2004. Disponível no Arquivo online da Folha de S. Paulo's em http://www.folha.uol.com.br [acesso restrito] [Jan 05] 